\title{
Belo Horizonte: o museu histórico da cidade e sua atual política de acervo
}

Thaïs Velloso Cougo Pimentel ${ }^{1}$, José Neves Bittencourt ${ }^{2}$, Luciana Maria Abdalla Ferron ${ }^{3}$

Em texto já bastante conhecido, o teórico de museus Ulpiano Toledo Bezerra de Meneses esclarece que essas instituições são espaços onde se constrói uma intermediação institucional entre a sociedade e objetos materiais retirados do ciclo da mercancia. Segundo Meneses, a evocação, característica dos museus de história até certa época, deve estar presente, mas não como objetivo institucional. Tirada dos museus essa característica, ela deve ser colocada como objeto de conhecimento ${ }^{4}$. Essa característica, entretanto, é matricial na formação do acervo de quase todos os museus de história. Não é diferente com o Museu Histórico Abílio Barreto, atualmente unidade da Fundação Municipal de Cultura da Prefeitura de Belo Horizonte.

Este artigo tem por objetivo discutir uma questão que pode ser considerada decorrente daquela citada por Meneses: como um museu pode ultrapassar a visão evocativa e celebrativa, transformando seu acervo - ou seja, transformando a si mesmo - em objeto de conhecimento, e, por conseguinte, em base para o conhecimento sobre a cidade? E que providências podem ser tomadas para que esse curso seja mantido? A evocação, qual seja, a recuperação por meio da memória, e a celebração, a homenagem solene de um evento ou data como forma de reforçar a lembrança, são características dos museus e não devem ser ignoradas. Entretanto, colocá-las sob crítica é também uma necessidade, e, mais além, a única forma de lutar contra a estagnação.

\section{3 - O Museu posto diante de si mesmo}

Criado oficialmente em 1941, como Museu Histórico de Belo Horizonte, e inaugurado em 18 de fevereiro de 1943, as origens do Museu

1 Professora Adjunta da Universidade Federal de Minas Gerais e Presidente da Fundação Municipal de Cultura da Prefeitura de Belo Horizonte. e-mail: tvcougo@gmail.com

2 Professor do Departamento de Museologia da Universidade Federal de Ouro Preto e pesquisador do Instituto do Patrimônio Histórico e Artístico Nacional (Iphan). e-mail: bitten.jn@gmail.com

3 Chefe de Gabinete da presidência da Fundação Municipal de Cultura da Prefeitura de Belo Horizonte. e-mail: lucianaferron@ig.com.br

4 MENESES, Ulpiano T. B. de. Para que serve um museu histórico?. In: MUSEU Paulista da Universidade de São Paulo. Como explorar um museu de história?. São Paulo: Museu Paulista/USP, 1992. p. 1-2. 
Histórico Abílio Barreto datam de 1935. Nessa ocasião, o jornalista e escritor Abílio Barreto ${ }^{5}$, convidado a organizar o Arquivo Municipal, encontrou diversos objetos, dispersos entre os documentos públicos. Foi quando Barreto começou a formar uma coleção, com objetos - documentos, entre pinturas, esculturas, instrumentos de trabalho, fragmentos de arquitetura, fotografias, plantas, mapas, etc. -, visando a formar o núcleo original de um futuro museu da história da cidade. A partir de 1941, já nomeado diretor da instituição, dedicou-se de maneira mais sistemática à reunião desses acervos, que viriam a ser transferidos, em 1943, ao local escolhido para sediar o Museu, a casa da antiga Fazenda do Leitão ${ }^{6}$.

Esse recolhimento sistemático empreendido por Barreto acabou por determinar o estabelecimento de uma política de acervos para o Museu Histórico de Belo Horizonte que, embora nunca formalizada, existiu antes mesmo de sua instalação. Os objetos, considerados então "preciosidades históricas e artísticas", eram aqueles remanescentes do Arraial de Belo Horizonte, antigo Curral Del Rei, além dos objetos referentes à jovem capital, Belo Horizonte, construída e inaugurada no final do século XIX. Esse acervo foi, em um primeiro momento, organizado em duas seções, sendo a primeira constituída pelos objetos procedentes do Arraial até a data da inauguração de Belo Horizonte, inclusive objetos e documentos da Comissão Construtora da Nova Capital, e a segunda, por peças referentes à Nova Capital. Quando foi inaugurado o Museu, a organização do acervo incluía uma terceira seção constituída de objetos relativos a Minas Gerais, especialmente Ouro Preto, antiga capital do Estado, e ao Brasil ${ }^{7}$.

5 Abílio Velho Barreto (Diamantina, 1882 - Ouro Preto, 1959) veio para Belo Horizonte em 1895. Autodidata, tinha o serviço público como primeira ocupação e dedicava-se a pesquisas sobre a história da cidade e também à literatura e ao jornalismo. Sua obra maior, Belo Horizonte: memória histórica e descritiva, foi lançada entre 1926 e 1936 e dividia-se em dois volumes: o primeiro, História antiga, e o segundo, História média. Baseado em extensa pesquisa documental, "Barreto mirava-se no exemplo de Diogo de Vasconcelos, tido como fundador da historiografia mineira e que em 1901 publicara a primeira versão da História Antiga das Minas Gerais e, em 1918, a História Média das Minas Gerais." (FARIA, Maria Auxiliadora. Belo Horizonte - Memória Histórica e Descritiva: à guisa de uma análise crítica. In: BARRETO, Abílio. Belo Horizonte: memória histórica e descritiva - história antiga e história média. Belo Horizonte: Fundação João Pinheiro; Centro de Estudos Históricos e Culturais, 1995 [1936]. 2 v.,v.l, p. 28)

6 CÂNDIDO, Maria Inês. MHAB: 60 anos de história. A construção do lugar e a criação da memória. Fundação e consolidação do Museu - 1935/1946. In: PREFEITURA Municipal de Belo Horizonte. MHAB: 6o anos de história. Caderno 2. Belo Horizonte: Museu Histórico Abílio Barreto, 2003. p. o9-12.

7 SANTOS, Gilvan Rodrigues dos; COSTA, THIAGO Carlos. O futuro do passado da cidade. A formação do núcleo original do Acervo Museu Histórico de Belo Horizonte. Anais do Museu Histórico Nacional. Rio de Janeiro, v. 38, p. 213-230, 2006. 
Traçadas e aplicadas essas diretrizes e objetivando reunir informações técnicas e administrativas que pudesse aplicar ao novo museu, Barreto realizou visitas a instituições do Rio de Janeiro, sendo o Museu Histórico Nacional a que lhe despertou maior atenção. A partir das observações que fez, Barreto elaborou o Regulamento do Museu Histórico de Belo Horizonte, documento que, dentre outras coisas, definia a linha de recolhimento do acervo, estabelecendo a transferência para o Museu de obras de arte, objetos, livros, documentos e folhetos existentes em todas as repartições da prefeitura. Mesmo adotado informalmente, o Regulamento funcionou, durante os primeiros anos do Museu, como uma referência geral, sobretudo em relação à natureza das incorporações a serem feitas ${ }^{8}$.

A política de acervo então implementada pela direção do Museu Histórico de Belo Horizonte articulava-se aos preceitos estabelecidos, de forma mais ampla, pela política de patrimônio em âmbito nacional:

Ao iniciar seu trabalho de "arqueologia histórica", recolhendo "objetos-relíquia" remanescentes do velho arraial e objetos reconhecidos como "ruínas precoces" procedentes das alterações da paisagem urbana da jovem Capital, Abílio Barreto, portanto, deu forma ao acervo embrionário do Museu da cidade. Sua ação fazia coro a um discurso oficial sobre museu e patrimônio histórico, à época em efervescência no país, que tomava o passado como veículo para a solução de problemas do presente e que definia o que devia ser lembrado e esquecido, no "jogo de lembranças e esquecimentos" da memória nacional. ${ }^{9}$

A análise da documentação guardada pelo Museu Histórico Abílio Barreto permite-nos observar que as diretrizes adotadas para o recolhimento do acervo que deu origem à Instituição permaneceram norteando a política de aquisição nas décadas que se seguiram à sua abertura ao público até os anos 1990. Nesses tempos, poucas foram as iniciativas de recolhimento de acervos, embora devam ser apontados o empenho e a dedicação de sucessivos diretores e equipes, que tentaram, ainda que diante de inúmeras dificuldades, manter a integridade e dinamizar os bens integrantes do Museu. É significativo o

8 BitTencourT, José N.; FERRON, Luciana Maria Abdalla, PIMENTEL, Thaïs Velloso Cougo. A teoria, na prática, funciona. Gestão de acervos no Museu Histórico Abílio Barreto. Revista CPC, São Paulo, n. 3, novembro 2006/abril 2007. p. 97. Disponível em http://www.usp.br/cpc/vi/php/wfo7_revista_interna.php?id_ revista $=7$ \&tipo $=6 \&$ id_conteudo $=3$ Acesso em: 26 fev. 2008.

9 CÂNDIDO, Maria Inês, TRINDADE, Silvana Cançado. O acervo de objetos do MHАB. Formação, caracterização e perspectivas. In: PIMENTEL, Thaïs Velloso Cougo (Org.). Reinventando o MHAB: o museu e seu novo lugar na cidade - 19932003. Belo Horizonte: Museu Histórico Abílio Barreto, 2004. p. 145-146. 
exemplo de Mário Lúcio Brandão, sucessor de Barreto, diretor da Instituição entre 1946 e 1959. Brandão destaca-se por apresentar propostas inovadoras para a época, como a incorporação da Igreja São Francisco de Assis ao Museu ou, ainda, a ampliação do conceito do Museu Histórico de Belo Horizonte, o que o tornaria uma instituição voltada para especializações diversas, todas referentes a Minas Gerais. Concretamente, sua administração, no entanto, seguiu as diretrizes formuladas pelo fundador, sobretudo no que concerne às incorporações e às formas de aquisição, baseadas em doações feitas por particulares e transferências da prefeitura. Já nas décadas seguintes, até os anos 1990, o Museu Histórico perderia muito do vigor institucional que marcou seus primeiros anos. Àquela altura, poucas eram as iniciativas voltadas para o recolhimento de acervos e para o aprimoramento de sua gestão, o que, de certa forma, definiu um período de estagnação da Instituição ${ }^{10}$.

A partir de 1993, com a instauração do chamado "processo de revitalização"11, foi formada uma equipe técnica composta por especialistas, que deu início aos trabalhos de análise e crítica desse acervo, o que significou, concretamente, a implementação do projeto de inventário do acervo do MHAB e a realização de pesquisas sobre as coleções. Conhecidas as características das acumulações de objetos preservados, suas lacunas e possibilidades, pretendia-se, então, estabelecer as bases e condições para a adoção de uma efetiva política de acervos no Museu.

À idéia de objetos autênticos e típicos, ilustrativos de uma história celebrativa, na qual não há lugar para diferenças ou conflitos, o "processo de revitalização" contrapunha a proposta de ampliar os horizontes de abordagem histórica e a natureza do acervo, conferindo ao Museu uma concepção de história socialmente mais generosa, com vistas ao "desenvolvimento de uma consciência crítica sobre o passado e o presente da cidade". ${ }^{12}$

10 BitTencourt, José N.; FERron, Luciana Maria Abdalla, PIMENTEL, Thaïs Velloso Cougo. A teoria, na prática, funciona. Gestão de acervos no Museu Histórico Abílio Barreto. op. cit.

11 Trata-se do processo de reformulação conceitual, metodológica, infraestrutural e administrativa do Museu Histórico Abílio Barreto, iniciado em 12 de março de 1993 com a reunião do Fórum de Discussão e Elaboração de Propostas. Esse processo teve a duração de dez anos. Para uma memória bastante detalhada, cf. PIMENTEL, Thaïs Velloso Cougo (Org.). Reinventando o MHAB: o museu e seu novo lugar na cidade - 1993-2003. op.cit.

12 JULIÃO, Letícia. Visitando o futuro: o museu da cidade, dez anos depois. In: PIMENTEL, Thaïs Velloso Cougo (Org.). Reinventando o MHAB: o museu e seu novo lugar na cidade - 1993-2003. op. cit., p. 176. 


\section{O conhecimento sobre o Museu como marco de uma nova política para o Museu}

É importante ressaltar que o "processo de revitalização" consistiu no desenvolvimento de uma série de ações institucionais encadeadas, entre os anos de 1993 e 2002, que objetivaram a modernização do Museu e dos diversos serviços por ele prestados. Isso significou a reorganização de todos os serviços técnicos da Instituição, bem como a criteriosa análise e revisão do discurso contido no acervo e nas exposições até então apresentadas. A res-significação desse acervo acarretou também a renovação das propostas expositiva e educativa do MHAB. As discussões e decisões em torno da necessidade de se abandonar uma concepção celebrativa do passado, e dar lugar a uma visão crítica, capaz de considerar a multiplicidade das experiências vividas no espaço urbano, do passado e do presente, imprimiram nova abordagem aos projetos, influenciando também a própria concepção das exposições e dos serviços educativos. Datam do período do "processo de revitalização", no âmbito da política de acervos, a intensificação das ações de identificação e recolhimento de itens relativos à Belo Horizonte centenária e de milhares de objetos-documentos. A coleção fotográfica sob guarda da Instituição foi consideravelmente aumentada, além de passar por rigoroso processo de conservação, e foram incorporados arquivos pessoais de ex-funcionários (inclusive o arquivo pessoal de Barreto) ${ }^{15}$, que, além de permitirem uma visão mais abrangente da cidade, foram inestimáveis para a compreensão da formação do acervo. A implantação da unidade de extensão do MHAB na Catedral da Boa Viagem, em 1999 e 2000, pode ser também considerada ação de grande importância, pois constituiu a primeira experiência de saída do Museu ao encontro da cidade. Nessa edificação religiosa foram colocados em exposição de longa duração dois bens integrantes do acervo que sobreviveram à demolição da edificação setecentista que, durante certo tempo, resistiu à destruição do Arraial do Curral Del Rei.

Muito marcante para a reestruturação do Museu foi o reconhecimento e tratamento conceitual do "Casarão" como peça mais importante do acervo. Essa indicação já estava presente desde a época da criação do Museu, e a

13 Trata-se aqui da incorporação do arquivo privado Ab́lio Barreto, composto por aproximadamente 14 ooo documentos, como manuscritos, cartas, documentos funcionais e fotografias, e da coleção Raul Tassini, também reunindo aproximadamente 10 ooo itens, como correspondências, desenhos, anotações, fotografias e recortes de jornais. Barreto e Tassini conviveram no MHBH durante algum tempo; o segundo parece ter sido um especialista amador em temas relativos ao folclore, $\mathrm{e}$ Barreto, nos temas ligados à história. Em 1943, uma discordância entre os dois resultou na demissão de Tassini, que acabou tentando organizar um museu privado, com milhares de itens que recolhia em andanças solitárias pela cidade. 
documentação restante desse período apresenta a ideia de que "a antiga sede da Fazenda do Leitão deveria ser tratada e valorizada como peça do acervo, certamente a mais emblemática do Museu, o que lhe daria a prerrogativa de se tornar o registro número I no Livro de Tombo da instituição" ${ }^{14}$.

$\mathrm{O}$ ano de 2003 pode ser visto como um marco importante na história recente do MHAB. Com os resultados da revitalização institucional já perceptíveis, ao completar 60 anos de sua fundação, a Instituição empreendeu densa reflexão sobre a sua trajetória - passado, presente e, principalmente, futuro. Determinada pela direção do MHAB a preparação de uma exposição de média duração tendo como tema justamente a história do Museu, a equipe técnica debruçou-se sobre a tarefa de examinar um conjunto documental amplo e variado. Esse conjunto, guardado no Arquivo Administrativo do Museu, contemplava as origens e a história administrativa pelo período de seis décadas ${ }^{15}$.

Esse trabalho, entretanto, não era pioneiro. Desde a segunda metade dos anos 1990, ampla e sistemática pesquisa sobre o acervo institucional havia permitido uma apreciação tanto sobre os itens individuais quanto sobre as coleções que o compunham. Ao examinar o conteúdo simbólico expresso nos objetos, de modo a compreender como representavam a rica e complexa experiência da constituição da cidade de Belo Horizonte e de sua história centenária, e estabelecer a relevância de sua guarda pela Instituição, os pesquisadores do Museu viram-se frente a novos problemas.

Inicialmente, constataram-se as limitações do acervo, quando examinado à luz dos problemas postos pela contemporaneidade da experiência da cidade e de seus moradores. Os objetos guardados pela Instituição falavam principalmente de um tempo passado, do planejamento e formação da cidade. Para além desse problema, os conjuntos de objetos preservados não davam conta das contradições e embates do cotidiano, expressavam um processo histórico aparentemente linear, no qual não se observava nenhuma espécie de contradição ${ }^{16}$.

14 CÂNDIDO, Maria Inês. MHAB: 60 anos de história. A construção do lugar e a criação da memória. Fundação e consolidação do Museu - 1935/1946. In: PREFEITURA Municipal de Belo Horizonte. MHAB: 6o anos de história. op. cit., p. 10.

15 Para uma visão geral sobre o processo de reflexão realizado pelos técnicos do MHAB, em torno dos 60 anos da instituição, cf. PREFEITUR A Municipal de Belo Horizonte. MHAB: 60 anos de história. op.cit. Segundo as pesquisadoras responsáveis pela redação do relatório final, “[a] aproximação do 6oo aniversário do MHAB, em fevereiro de 2003 , trouxe a oportunidade de se realizar um amplo projeto de pesquisa sobre o tema MHAB: 60 anos de história. Assim, em 2002, toda a equipe debruçou-se sobre os arquivos administrativos e, pela primeira vez, pôde desvendar ou conferir novos significados a atores."

16 A primeira exposição montada pelo então MHBH, sob supervisão de Barreto, buscava combinar a monumentalização do "Casarão" com a apreciação de relíquias sobre 
$\mathrm{O}$ acervo do MHAB parecia falar de uma história que caminhara sempre em sentido positivo, sugerindo uma linearidade e continuidade do processo histórico da capital de Minas e deixando em discreto segundo plano o fato de que o chão da cidade foi e será sempre campo de forças dos que lutam por reconhecimento e perpetuação. Diante de questões colocadas pela pesquisa científica e pelo avanço das ciências humanas, os documentos reunidos sob o olhar criterioso de Barreto e de seus seguidores mais provocavam novas perguntas do que se mostravam capazes de responder aquelas formuladas por pesquisadores internos e externos, ou mesmo pelos visitantes que se mostrassem mais atentos para o conteúdo das exposições.

As comemorações em torno dos sessenta anos da Instituição mostraram-se oportunas para refletir sobre sua inserção na contemporaneidade. Como um museu, cujo acervo falava principalmente do passado da cidade, poderia representar sua história recente? Desde os anos de 1940, passados os primeiros anos da reunião das coleções originais, o recolhimento tornou-se fato eventual na Instituição. A incorporação de novos itens era muito mais produto do gesto espontâneo dos doadores do que da reflexão sobre a vocação e as potencialidades do Museu.

Em resumo, a equipe técnica viu-se diante da necessidade de compreender a maneira como a cidade e seus moradores eram representados no acervo institucional. Dado o fato de que o acervo - como de resto, a Instituição - estava estagnado, a pergunta seguinte era se o Museu, em um futuro não muito longínquo, seria capaz de representar a atividade humana responsável pela trama cotidianamente urdida pelos diversos agentes sociais responsáveis pelo desenvolvimento da cidade, trama que se tornava cada dia mais complexa.

O conhecimento possibilitado pelo inventário realizado nos anos 1990 permitiu que alguns problemas começassem a ser dimensionados. Um deles parecia saltar aos olhos: algumas coleções importantes para a compreensão da história da cidade, como era o caso da documentação produzida pela Comissão Construtora da Nova Capital, encontravam-se dispersas em instituições diferentes, à espera de um projeto que propusesse seu tratamento unificado.

\footnotetext{
o passado de Belo Horizonte. O partido dessa exposição era ipsis literis baseado no volume 1 da obra histórica de Barreto, na qual a povoação colonial era tomada como antecedente da nova capital. O conjunto de contradições malresolvidas, como, por exemplo, a destruição do casario e o deslocamento da população local para os arredores da nova capital, foi totalmente ignorado. (cf. BITTENCOURT, José N. MHBH, МНАВ, MhАB. O sítio da Fazenda Velha do Leitão, seus diversos prédios e seus museus, 1943-20oo. In: PIMENTEL, Thaïs Velloso Cougo (Org.). Reinventando o MHAB: o museu e seu novo lugar na cidade - 1993-2003. op.cit., p. 40-41.
} 
Esse foi o mote de um importante seminário realizado em 2003 pela então Secretaria Municipal de Cultura, cujo objetivo era justamente discutir propostas para a elaboração de uma política municipal de recolhimento, guarda e tratamento de acervos históricos. Esse seminário permitiu o debate e o levantamento de problemas a serem enfrentados pelos diferentes órgãos não apenas municipais, mas também do estado de Minas Gerais, que têm a responsabilidade de cuidar de acervos históricos. Alguns desdobramentos importantes dessa discussão puderam ser sentidos nos anos posteriores quando, por exemplo, o Museu Histórico Abílio Barreto, o Arquivo Público da Cidade de Belo Horizonte e o Arquivo Público Mineiro, instituições de âmbito municipal, as duas primeiras, e estadual, a última, propuseram e aprovaram um projeto junto à Fapemig (Fundação de Amparo à Pesquisa de Minas Gerais) com o objetivo de dar tratamento unificado ao acervo da Comissão Construtora, cuidando não apenas das estratégias de sua preservação, mas também, e principalmente, de seu acesso ${ }^{17}$.

Além dessa iniciativa, no MHAB ganhava força a reflexão sobre a natureza, abrangência e limites do acervo, tendo em vista principalmente o entendimento cada vez mais claro da vocação da Instituição como museu de cidade. No entendimento do corpo técnico, a vocação original de museu histórico não mais dava conta das demandas feitas ao Museu pelos agentes sociais. A história é, por certo, produto de uma necessidade social, sendo que, no entender de alguns especialistas, "mesmo as sociedades humanas mais simples precisam de história, e as sociedades complexas de nossos dias precisam de um monte de história. Para atender tais necessidades, as sociedades juntam os restos e os detritos da experiência e das atividades humanas"18. O problema é que a história, como ciência, tem-se tornado cada vez mais abrangente, sendo que, em um limite cada

17 Entre 2001 e 2004, em uma iniciativa de parceria entre as três instituições responsáveis pela guarda do acervo da Comissão Construtora da Nova Capital, foi realizado o projeto Acervo da Comissão Construtora da Nova Capital, que consistiu na microfilmagem e digitalização de toda a documentação e na construção de uma base de dados comum, reunindo todos os registros em um único sistema de busca. O banco de dados aqui disponível é o resultado desse projeto, patrocinado pela Fapemig. Realizando a pesquisa por esse sistema, o usuário tem acesso às imagens digitalizadas de todos os documentos gerados pela Comissão Construtora, independente do local de guarda dos originais. O resultado da iniciativa pode ser consultado em http://www.comissaoconstrutora.pbh.gov.br (Acesso em: or mar. 2008). Para maiores informações sobre o Projeto CCNC, cf. GOMES, Maria do Carmo Andrade; CARNEIRO, Edilane Maria de Almeida; PIMENTEL, Thaïs Velloso Cougo. Uma experiência interinstitucional. Revista do Arquivo Público Mineiro, Belo Horizonte, n 2, p. 177-189, julho-dezembro 2007.

18 KAVANAGH, Gaynor. History curatorship. Washington DC: Smithsonian Institution Press, 199o. p. 4 . 
vez mais próximo, tudo será de interesse da história. Assim, quais os limites do acervo reunido por um museu que se pretende "de história"? E se esse museu for o museu de história de uma cidade? A questão é que essa "necessidade de história" acaba tornando-se palco de luta e gerando todo um aparato voltado para tais necessidades:

Porque as sociedades precisam de visões específicas e apropriadas, e porque não existe uma coisa chamada memória orgânica, um conhecimento puro e inocentemente passado adiante, um grupo de funcionários e um aparato têm de ser desenvolvidos para essa função. Assim, existem, em algumas sociedades, contadores de histórias, sacerdotes e bardos, bem como arquivistas, historiadores e curadores de museus em outras. Todos eles existem para suprir a necessidade de memória, lembrança e reconhecimento. Seus métodos envolvem um cuidadoso arranjo e interpretação de fragmentos de informação e imagens legados pela vida no passado. ${ }^{19}$

Visto então que os museus são uma necessidade social, como devem posicionar-se diante dessa necessidade?

No ano de 2003 um Fórum de discussões em torno da política de acervos do МHAB foi organizado na Instituição. Os debates envolveram o convite de um consultor e de um público principalmente composto de técnicos e gestores de instituições de memória da cidade. Após dois dias de discussões com o público mais ampliado e um dia de trabalho da equipe do MHAB e do consultor Dr. José Neves Bittencourt, chegouse a um documento final que apontava propostas e recomendações. ${ }^{20}$

Basicamente foram destacadas três linhas de atuação com base na definição de acervo tradicional, acervo não-formal e acervo operacional, que pudessem orientar uma política de acervos da Instituição. Entendendo a necessidade de dar continuidade ao trabalho tradicionalmente desenvolvido pelo Museu, via-se como essencial a tentativa de complementação das coleções existentes. Mais do que isso, o fórum apontava para a pertinência de uma ação mais efetiva em torno de dois conceitos novos: o de acervo não formal, que deveria emergir de projetos calcados na mediação entre a equipe técnica do MHAB e a população de Belo Horizonte, com vistas a

19 Idem, ibidem, p. 4.

20 MUSEU Histórico Abílio Barreto. Fórum de discussões. Política de Acervo do MHAB. Belo Horizonte, 2oo3. 6p MS. Disponível no Arquivo Administrativo do Museu Histórico Abílio Barreto. 
democratizar a definição de acervo a ser adquirido pelo Museu; e o de acervo operacional, por meio do qual se entendia que espaços, paisagens, estruturas, monumentos e equipamentos da cidade deveriam ser passíveis de tratamento museológico.

Além disso, o fórum recomendava, com destaque, a necessidade da criação tanto de uma Comissão de Política de Acervo como a de um "manual de campo", que deveria normatizar os procedimentos relativos à aquisição de acervo. Ficou ainda definido que o Museu deveria dar início a ações experimentais de aquisição de acervo, tais como uma campanha de recolhimento de fotos de Belo Horizonte junto aos seus próprios funcionários e o recolhimento de objetos pertencentes aos prefeitos da cidade, entre outros.

\section{Entre uma política e outra - a instituição da CPPA e a nova abordagem dos acervos}

Instituída formalmente por meio da Portaria SMC no 006 de 08 de outubro de 2003, a Comissão Permanente de Política de Acervo do MHAB (CPPA) cuidou inicialmente de encaminhar decisões do fórum, como a campanha de recolhimento de fotos e a definição da praça Sete de Setembro como acervo operacional. Outra importante frente de trabalho foi a resolução de pendências: como o próprio nome sugere, tratava de definir um esforço concentrado da equipe do Museu em torno de questões, fossem de recolhimento, transferência ou descarte de acervo, que aguardavam posicionamento da Instituição havia algum tempo.

As novas ações sugeridas pela CPPA, todas elas vinculadas a projetos formulados na Instituição, permitiram que, ao longo desses cinco anos, a equipe técnica do Museu experimentasse uma dinâmica bastante rica de debates e de confronto com situações novas que exigiram posicionamentos claros.

O dia-a-dia dos trabalhos, por exemplo, colocou em xeque questões relativas à originalidade, expressividade, pertinência, condições de preservação, possibilidade real de guarda de acervos, tanto os tradicionalmente guardados na Instituição, como aqueles em busca de reconhecimento.

No interior da CPPA, há quase cinco anos, os debates têm levado em conta várias questões teóricas: a memória e as suas infindáveis formas de manifestação; a construção e a escrita da história como disciplina e legado para as sucessivas gerações; a riqueza da experiência urbana e os limites da sua tradução em acervos institucionais; a multiplicidade e a diversidade do fazer humano frente à incapacidade de tudo preservar; as dificuldades na conceituação e definição do que deve ser entendido 
como patrimônio em um tempo de excessos; as possibilidades técnicas da preservação e seus limites.

A cada gesto cidadão de um morador de Belo Horizonte, que busca o Museu para a doação de acervo, uma grande quantidade de questões invade as reuniões da CPPA. Por vezes, somos apenas capazes de formular perguntas, sem, no entanto, conseguir respondê-las. Noutras, posicionamo-nos claramente pela incorporação ou por sua recusa. O que basicamente tem iluminado as discussões da CPPA é o entendimento de que somos órgão público responsável pelo cuidado com a memória da cidade em que vivemos. Porque a compreendemos sempre no plural, o desafio maior é quase sempre o da seleção. Afinal, praticar política pública de preservação é também, o tempo todo, fazer escolhas. E as escolhas são feitas não apenas nas situações de ter que responder (às solicitações de doação, por exemplo), mas também quando somos instados a olhar de maneira especial, seja para um morador da cidade, em função de sua projeção pública ou reconhecimento, seja para uma forma de manifestação política, artística, cidadã, enfim. Nesses casos, o Museu busca conhecer, aproximar-se, reconhecer o mérito e solicitar a doação de objetos em suportes variados que possam expressar o conteúdo simbólico das ações que os geraram.

A cidade, ela mesma, e não mais apenas a sua história, foi feita objeto de reflexão no МHAB. Isso significa que a Instituição tem praticado uma política de acervos que lança olhos para os processos, além, evidentemente, de reconhecer pessoas, documentos, objetos utilitários ou artísticos como integrantes desses processos. Mas, muitas vezes, são justamente os processos que atraem a atenção; os objetos deles oriundos passam a ser valorizados muito mais pelo seu conteúdo simbólico que por seu caráter excepcional. Assim, por exemplo, telas em grandes dimensões trabalhadas por grafiteiros de Belo Horizonte foram incorporadas ao acervo do МНАВ porque resultaram de uma oficina, onde a cidade foi tomada como objeto de reflexão e apreensão. Uma coleção de cerca de 4000 cartões postais publicitários acresceu a coleção de postais do Museu porque a CPPA entendeu que uma empresa de publicidade de Belo Horizonte lançou mão de uma forma de expressar a cidade, pelo viés publicitário. Essa forma é bastante atual em sua proposta, conteúdo e alcance, e mais: pode e deve ser percebida como reflexo do tempo que a gerou.

Trata-se, possivelmente, do futuro do Museu, posto em tela no presente.

Mudanças econômicas e políticas continuam a influenciar a maneira como o passado é lembrado e o grau de interesse do público por ele. [...] Se as mudanças sociais e econômicas tornam-se cada 
vez mais frenéticas, o passado surgirá mais fortemente na imaginação popular. Isto poderá criar pressões por formas específicas de história nos museus. ${ }^{21}$

Falar nesse tipo de pressão equivale a falar na memória como objeto de disputa pelo poder, e nos acervos como resultado final dessa luta. Atualmente, no mínimo, pode-se dizer que os museus, suas equipes e os diversos pesquisadores que tomam essas instituições como objeto de reflexão têm muito maior consciência sobre as questões de origem, potencialidades e limites dessas instituições, bem como da luta silenciosa que subjaz a elas. Não é pouca coisa: se 1922 foi o momento de consolidação dos museus de história no Brasil, e os anos seguintes foram os da implantação de grande número dessas instituições, tornando-se o Museu Histórico Nacional a instituição referencial, nesse campo, os anos 1980 e 1990 foram os da reformulação crítica - reformulação que atingiu fortemente os acervos, seja pela via da interpretação, seja pela via da busca de novos campos de recolhimento de acervos. Neste sentido, a relação com a cidade revitalizada da reestruturação do Museu.

Vale aqui recorrer ao importante teórico do campo museal, Hughes de Varine. Suas formulações estiveram, ainda que indiretamente, nos fundamentos do "processo de revitalização" do MHAB, em 1993. Suas formulações sobre a inovação e os fenômenos culturais em diferentes meios da sociedade francesa e a avaliação dos modos de intervenção, no processo, dos poderes públicos, publicadas em um pequeno e pouco conhecido livro ${ }^{22}$, ainda hoje merecem toda a atenção. $\mathrm{O}$ "processo de revitalização" implicou buscar a cidade como coletividade, o que resultou em "viver com, agir com, refletir com pessoas implicadas no combate comunitário cotidiano"23. Os objetivos de Varine, ao longo de dez anos de trabalho de campo, eram muito mais amplos do que os do "processo de revitalização" do MHAB, mas apresentavam algumas possibilidades de comparação, principalmente no que diz respeito aos objetivos: reagir contra o discurso que esconde uma ideologia social de opressão, dar a palavra àqueles que trabalham no silêncio e trazer uma contribuição que só pode ser empírica ao método de intervenção social em uma estrutura comunitária ${ }^{24}$. É o que o MHAB e sua equipe vêm buscando no contexto de uma administração pública que, entre acertos e erros, comprometeu-se com a prática democrática.

21 KAVANAGH, Gaynor. History curatorship. op. cit, p. 167.

22 VARINE, Hughes de. O tempo social. Rio de Janeiro: Livraria Eça Editora, 1987.

23 Idem, ibidem, p. 18.

24. Idem, ibidem, p. 18. 


\section{Máquinas de escrever, garrafas de coalhada, caixas de sabonete - rumo ao compartilhamento de um "tempo social"}

A política de acervos, em última análise, deve refletir tal comprometimento. Assim, quando os pequenos objetos do cotidiano são examinados para aquisição, pela CPPA, são pensados não apenas como documentos potenciais para a salvaguarda e compreensão de modos de vida dispersos pela cidade, mas também como atos finais de uma divisão de "tempo social”.

Se o tempo biológico é quase o mesmo para todo mundo, se o tempo imposto tem uma forte conotação de classe, o tempo social este é realmente escolhido. Cada indivíduo é, ao menos teoricamente, livre para determinar a parte de seu emprego de tempo que será a ele consagrado [...], os objetivos visados e o tipo de ação conduzida. Ele poderá privilegiar tal ou tal nível, da responsabilidade educativa ao centro da célula familiar ao engajamento político nacional, passando por tal atividade associativa, pelas formações gerais complementares, por uma participação relativamente passiva, por um dinamismo militante, etc. ${ }^{25}$

Essa digressão de Varine vai ao encontro de certas ações desenvolvidas pelo MHAB, nos últimos anos, no sentido de reforçar seu lugar na cidade e diante dos cidadãos - no caso, pessoas que resolvem, espontaneamente, procurar o museu para encaminhar objetos para doação. Pode-se considerar que tal ação pressupõe o compartilhamento, com o Museu, de parte do tempo individual, parte essa que Varine denomina "tempo social”, um tempo que os indivíduos dispõem de maneira que acham justa e coerente.

O tempo social é um tempo de liberdade. É aquele da criação cultural. Se, para uma elite, criação significa produção de caráter estético ligada posteriormente a um patrimônio, para a massa de homens e mulheres de todos os tempos, ela é o domínio de uma vida cotidiana orientada para o futuro, conquista sempre necessária e sempre recomeçada, obra coletiva. ${ }^{26}$

Ora, a vida cotidiana é parte integrante da teia da história, e os milhões de nós da trama que formam a cidade, no museu, são constituídos pelos "objetos/documentos", inumeráveis produtos da cultura material submetidos à intervenção científica e laboratorial específica. A resposta de

25 Idem, ibidem, p. 67. Grifos do autor.

26 Idem, ibidem. p. 72. Grifos do autor. 
cidadãos comuns às ações do Museu pode ser considerada ato de criação cultural na medida em que leva essas pessoas a estabelecerem uma relação com a instituição; também pode ser considerada "trabalho da memória", já que essas pessoas procuram encaminhar seus objetos com a intenção de juntar memórias pessoais ao que é percebido como memória oficial e, dessa maneira, lutar contra o esquecimento.

De toda forma, o encontro de iniciativas individuais com a ação sistemática da CPPA, como intermediária entre o Museu e o público, parece, se levarmos em conta as considerações da especialista inglesa Gaynor Kavanagh, ser a forma mais eficaz de

fortalecer os laços com a comunidade local e aumentar a qualidade e o alcance das coleções, através da extensão de seus registros e atividades de aquisição e de sua integração com atividades educativas e exposições. A relevância social [das atividades dos museus] abre-lhes a possibilidade não somente de alcançar a população local, mas também de engajar uma audiência mais democrática do que os museus e exposições mais convencionais. ${ }^{27}$

Objetos utilitários, obras de arte, correspondência, livros, bordados, trabalhos escolares, monumentos e fotografias têm sido constantemente avaliados pela CPPA como expressão de um modo de ver, sentir e habitar a cidade. Às histórias neles contidas soma-se o trabalho dos técnicos do Museu que investigam, exploram, contrapõem versões, acrescentam dados que farão dos registros das vivências de alguns o documento a ser conhecido por muitos. Ao serem feitos objetos de museu, esses fragmentos poderão ser vistos e revistos por uma sucessão de gerações de curiosos e/ou estudiosos da história da cidade de Belo Horizonte.

27 KAVANAGH, Gaynor. History curatorship. op. cit., p. 170. 